\title{
Our Experience Indistal Radius Fractures with Percutaneous Pinning And Plaster In Postmenopausal Women As A Day Care Procedure
}

\author{
P Kosala Raman ${ }^{1}$, Dr. P. Balamurugan ${ }^{2}$, Dr. V. Ajay Karthick ${ }^{3}$ \\ Department Of Orthopaedics, Coimbatore Medical College, India.
}

\begin{abstract}
Background: Fractures at the distal end of radius accounts for around 18 to 20\% of all skeletal fractures occurring in adults and around $19 \%$ of all fractures in the postmenopausal females. ${ }^{1}$. The risk factors in this age group are generalized osteoporosis due to hormonal changes, underlying systemic disease, long term steroid intake $^{2}$ etc.

Aim: The aim of the study is to provide a pain free wrist and early restoration of activities of daily living with distal radius fracture in postmenopausal femalesas a day care procedure.

Materials \& Methods: In a prospective study, 20 patients with distal radius fractures were treated with the percutaneous pinning and plaster from July 2014- Dec 2015.All patients were evaluated with radiographs in anteroposterior andlateral views. All these fractures were closed. According to AO Classification ${ }^{7}$ there were Type A2 -13 cases; A3-1case;B1-2 and C1-4 cases. There were no any other associated injuries. All fractures were treated with closed reduction, percutaneous pinning and plaster.Follow ups included radiographs, clinical examinations, and recording wrist scores. The functional outcome of patients was assessed by using modified mayo wrist score ${ }^{9}$.

Results: After 18 months of follow up, the average mayo wrist score was found to be 86.53.Complications like reduced range of movements due to stiffness was found in 2 patients. There was no pin site infection,superficial radial nerve palsy and non-union.

Conclusion: Our data shows percutaneous pinning with $k$ - wire was found to be a minimally invasive day care procedure meeting the patient demands. The fracture union time on an average is found to be around 6 weeks. The anatomical reduction and radiological parameters are found tobe maintained by crossed pinning providingearly range of motion in wrist joint and successful functional outcome.
\end{abstract}

Key words: distal radius fracture, percutaneous pinning,osteoporosis

\section{Introduction}

Fractureat the distal end of radius accounts for around 18 to $20 \%$ of all skeletal fractures in adults and around $19 \%$ in the postmenopausal females ${ }^{1}$. Osteoporotic fractures are more common among the postmenopausal females due to the lack of estrogensupport ${ }^{1}$. The fracture is most vulnerable at the corticocancellous junction of distal end of radius where the trabecular bone is dominating and the cortical bone is thinner. Many factors causing this risk are increased osteoblastic and osteoclastic turnover rates, generalized osteoporosis,underlying systemic disease, long term steroid intake etc ${ }^{2}$.

Distal radius fractures that occur in elderly postmenopausal women arefive to six times more frequent than in males, and usually occur betweenthe ages of 55- 85 years, with the peak incidence between 70 to 80 years ${ }^{3}$.The distal radius fractures can occur in bimodal age groups (aged17-25 years) involved in sports activities undergoing a relatively high energysignificant fall, and in geriatric persons (aged $>50$ years) withosteoporotic bone undergoing a simple low velocity fall, stress or abump.

Fractureat the sites of osteoporotic bones is the major cause of morbidity among the postmenopausal women. Hormonal imbalances can result in rapid bone loss in postmenopausal woman ${ }^{4}$. Loss of balance between osteoclastic and osteoblastic activity leads to decreased bone mineral density. Annually there is around 5 percent of bone mineral loss and the loss peaks around the menopause ${ }^{3}$. Various methods of fixation have been used, including elastic intrafocal and extrafocal pinning, arthroscopic pinning, external fixation alone, external fixation and percutaneous pinning, buttress plating, volar locking compression plate ${ }^{5}$.Percutaneous pinning is a cost effective, minimally invasive day care procedure in maintaining reduction, stability, radiological parameters and providing early range of motion to wrist joint with least complications rate ${ }^{6}$.

This prospective study was our experience in treating osteoporotic distal radius fractures with percutaneous pinning and plaster. 


\section{Materials \& Methods}

Between July 2014 and December 2015, a total of 20 patients with distal radius fractures were treated with closed reduction andpercutaneous pinning and plaster. The age group in our study ranges from 45 years to 65 years (mean $=57.6)$. The mechanism of injury in all 20 patients was low energy self-fall on the outstretched hand. All were closed fractures. In our study sample, dominant right side was involved in 14 patients and left side in 6 patients. Inclusion criteria in this study were Postmenopausal women with displaced distal radius fractures. Exclusion criteria were open fractures, pathological fractures, children (0-14 years) and males, associated chronic co-morbidities. AO classification was used in our study ${ }^{7}$ and there were type A2 -13 cases; type A3-1case; type B1-2 and type C1-4 cases.

\begin{tabular}{|l|l|l|l|l|l|}
\hline & \multicolumn{5}{|l|}{ AO Classification } \\
\hline S.no & $\begin{array}{l}\text { Age } \\
\text { In } \\
\text { years }\end{array}$ & A2 & A3 & BI & C1 \\
\hline 1 & $45-50$ & 2 & - & - & - \\
\hline 2 & $50-55$ & 3 & 1 & 2 & 1 \\
\hline 3 & $55-60$ & 5 & - & - & 2 \\
\hline 4 & $60-65$ & 3 & - & - & 1 \\
\hline & & n=13 & n=1 & n=2 & n=4 \\
\hline
\end{tabular}

Table 1: Age and Fracture pattern

The patients were included with strict inclusion criteria without associated co morbidities like diabetes, hypertension, heart disease etc. Detailed clinical history and examination was done. Anteroposterior and lateral radiographs were taken preoperatively. In selected cases CT scan was done in order to know the extent of articular surface involvement. The patients were taken up for surgery on an emergency basis. The functional outcome was assessed by using the mayo wrist scoring system.Post-operative radiographs were evaluated for evidence of fracture union and complications. K wires were removed at the end of 6 weeks ${ }^{8}$.

\begin{tabular}{lr} 
Table 2 Modified Mayo wrist score for assessing functional outcome \\
\hline Parameter & Score \\
\hline Pain & 25 \\
No pain & 20 \\
Mild occasional & 15 \\
Moderate & 0 \\
Severe & \\
Work status & 25 \\
Regular job & 20 \\
Restricted job & 15 \\
Able to work but unemployed & 0 \\
Unable to work due to pain & \\
Range of motion & 25 \\
$7120^{\circ}$ & 20 \\
$100^{\circ}-119^{\circ}$ & 15 \\
$90^{\circ}-99^{\circ}$ & 10 \\
$60^{\circ}-89^{\circ}$ & 5 \\
$30^{\circ}-59^{\circ}$ & 0 \\
$0^{\circ}-29^{\circ}$ & \\
Grip strength (\% of normal) & 25 \\
$90-100$ & 15 \\
$75-89$ & 10 \\
$50^{\circ}-74$ & 5 \\
$25-49^{\circ}$ & 0 \\
$0-24$ & \\
\hline
\end{tabular}

\section{Interpretation}

1) $\square$ Scores between 90 to 100 are considered excellent

2) $\square$ Scores between 80 to 89 are considered good

3) $\square$ Scores between 65 to 79 areconsidered Fair

4) $\square$ Scores between less than 50 are considered poor.

5)
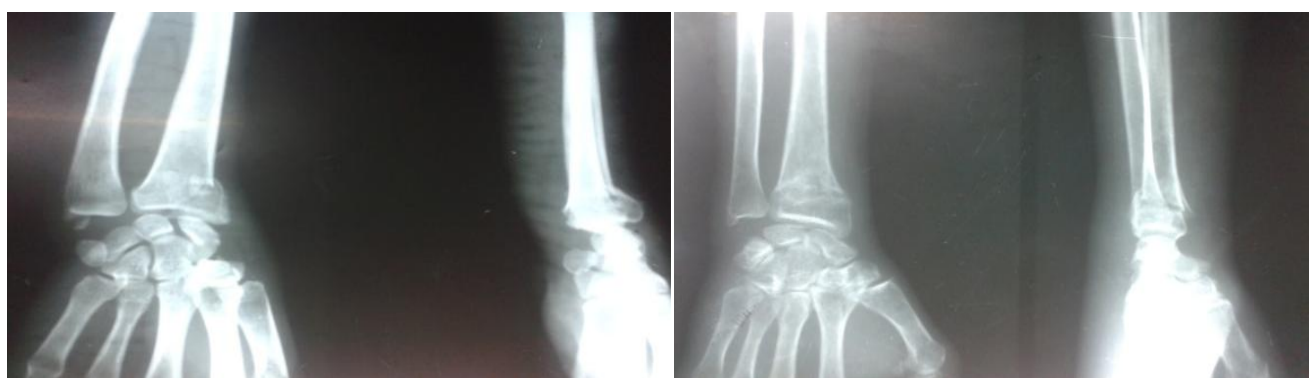

Fig 1 pre op x ray fig 2 pre op x ray type A2 


\section{Operative Procedure}

Anaesthesia - supraclavicular block,Position - supine position with wrist over the arm table.All steps are done under strict aseptic precautions and complete draping.

The principle step is near anatomical reduction of the fractured fragments by closed reduction. Anatomical reduction isobtained by traction and counter traction to correct impaction andaligning distal fragments by flexing the distal fragment in anteroposteriordirection reducing the dorsal angulation to neutral position and then reducing the ulnar deviation. These steps help to achieve the acceptable radial length, palmar tilt and radial inclination ${ }^{10}$.

Graham (1997) criteria were used in assessing radiological outcome. It includes on a posteroanterior (PA) view, radial shortening of less than $5 \mathrm{~mm}$ in involved side compared to opposite wrist joint, radial inclination of more than $15^{\circ}$, on the lateral view dorsal tilt of less than 15 degree and volar tilt less than 20 degrees, intra-articular fracture step-off less than $1 \mathrm{~mm}$, articular incongruity of less than $2 \mathrm{~mm}$. The position is checked under $\mathrm{C}$-arm foracceptable levels.The final corrected position with acceptable radiallength and radial inclination is maintained before $\mathrm{k}$-wire application.

K-wire of size 1.8 or $2 \mathrm{~mm}$ are inserted from lateral to medial starting from radial styloidprocess base crossing the fracture and holding the opposite cortex withthe assistant maintaining traction and reduction. Usually power drill was used to apply $\mathrm{k}$ wires and not with hand drill ${ }^{11}$. Another $\mathrm{k}$ wire is inserted from the sigmoid notch startingfrom dorsal cortex to the palmar cortex to avoid the wrist joint proper and to make sure that the kwire entersopposite intact volar cortex ${ }^{12}$. Additional $\mathrm{k}$-wires were insertedfrom dorsal to volar cortex to maintain stability in few cases ${ }^{12}$.

The reduction is checked under $\mathrm{c}-$ arm and the $\mathrm{k}$-wires arebent at around 90 degree with $\mathrm{k}$ wire bender and cut with $\mathrm{k}$ wire cutter.Pin site sterile dressings done and then below elbow plaster is applied in reduced position. All the patients were discharged on the same day of procedure.

\section{Post Operative Protocol}

Oral antibiotic like capsule amoxicillin 500mg tds and analgesics were given for 1 week. The patients are regularly followed-up at 2 weeks, 4weeks and 6 weeks for assessing any pin site loosening or infection tillpin removal ${ }^{13}$.The $\mathrm{x}$ - rays were taken periodically at 2 weeks interval for assessingthe radiological parameters ${ }^{14}$.

The plaster of Paris and percutaneous k-wires were removedafter 6 weeks of immobilization under strict aseptic precautions.Patients are then mobilized for active and passive motion exercisesand rehabilitation ${ }^{15}$. Physical rehabilitation therapy is continued until thepatient returns to her normal activities and regains a good hand grip ${ }^{16}$.

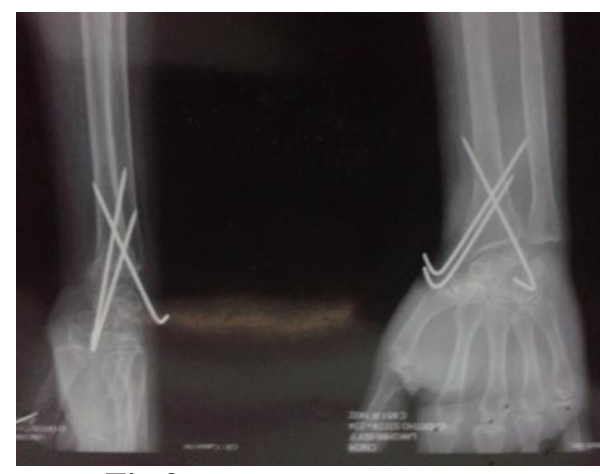

Fig 3 Post op x ray

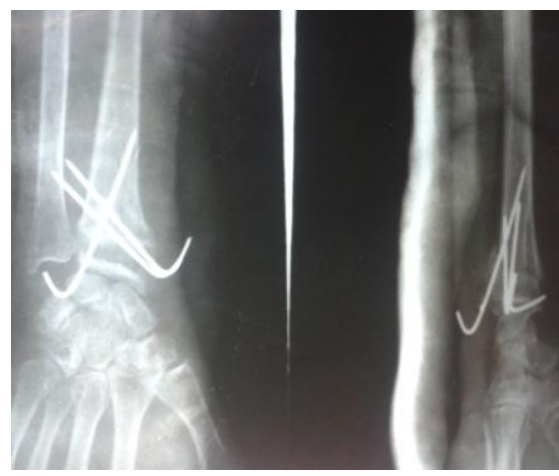

Fig 4 post op $\mathrm{x}$ ray

\section{Results}

In our study, themean age of postmenopausal women was 57.6 years. The average operative time was 20 minutes. All the cases were done as a day care procedure. The average follow up period was 6 months.

Among the total study sample of 20 postmenopausal women, $70 \%$ dominant right side and in $30 \%$ left side was involved .The average period of union was 6 weeks. The average radiological outcome at the end of the study was found to be radial length [9.5mm], radial inclination [20.23 degrees] and palmar tilt [9.33 degree].The average range of movements on final follow up was palmar flexion 75.38 degrees, dorsiflexion 77.69 degrees, radial deviation 18.23 degrees and ulnar deviation 23.46 degrees. The results were excellent in 10, good in 8 and poor in 2 cases. After 18 months of follow up, the average wrist score was 86.53. Complications like reduced range of movements due to secondary loss of reduction were found in 2 patients. There were no pin site infections, superficial radial nerve palsy and non-union. 
Our Experience Indistal Radius Fractureswith Percutaneous Pinning And Plaster...

\begin{tabular}{|l|l|l|}
\hline $\begin{array}{l}\text { Mayo wrist score } \\
\text { (Functional outcome) }\end{array}$ & No. of cases[n] & \%compared to total sample \\
\hline Excellent & $\mathbf{1 0}$ & $\mathbf{5 0 \%}$ \\
\hline good & $\mathbf{8}$ & $\mathbf{4 0 \%}$ \\
\hline Fair & - & - \\
\hline poor & 2 & $10 \%$ \\
\hline & \multicolumn{2}{|l}{} \\
\hline
\end{tabular}

Table 3 Functional outcome according to mayo wrist score

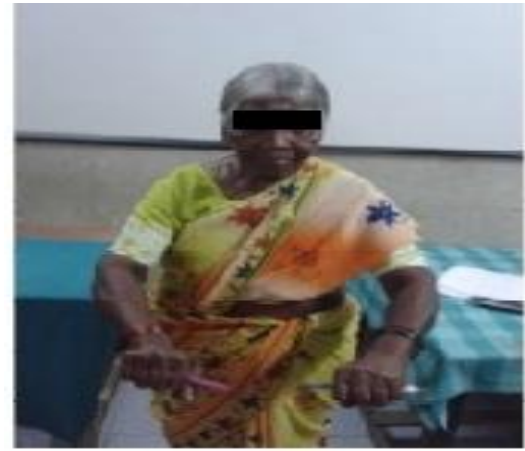

FRONATION

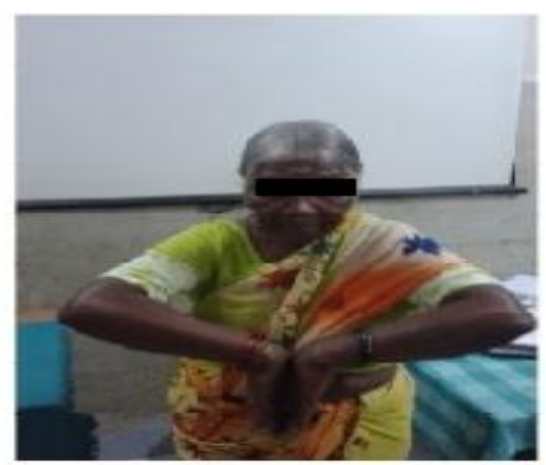

PAIMARFLEXION

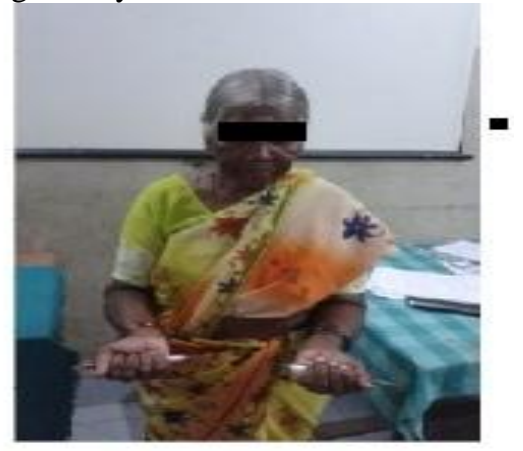

SUPRNATION

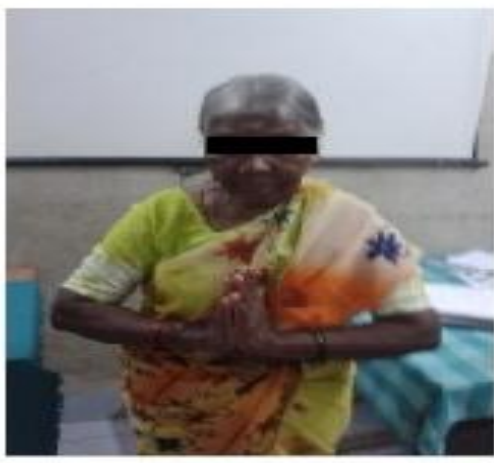

DORSIFLEXION

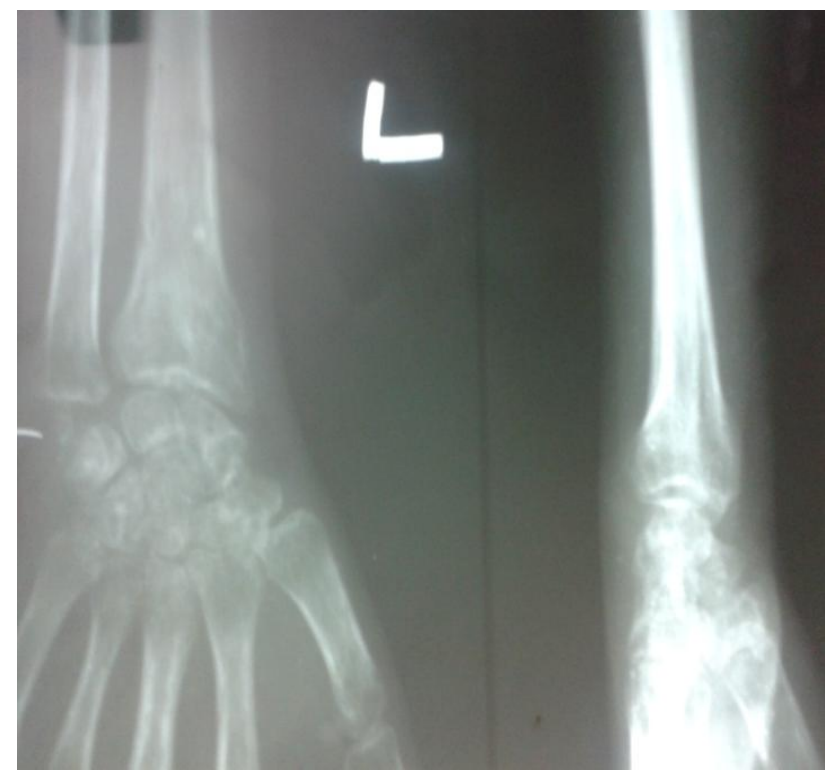

Fig 6 Final radiological outcome 


\section{Discussion}

Distal radius fractures are more common injuries occurring in geriatric population particularly among the postmenopausal women with underlying osteoporosis ${ }^{2}$. The mode of violence is mostly a low velocity fall during the household activities. High velocity injuries are mostly encountered during road traffic accidents ${ }^{2}$.

Majority of the fractures are said to be extra -articular displaced fractures $\{\text { mostly type A2 }\}^{7}$. Open surgical plating needs a lot of exposure and periosteal stripping when compared to closed reduction and $\mathrm{k}$ wire pinning $^{17}$. Bridging external fixator by ligamentotaxis usually leads to stiffness of wrist compared to $\mathrm{k}$ wire which provides early motion of the joint ${ }^{18}$. Pinning along with plaster mostly prevents the secondary loss of reduction which is common with pinning alone. Crossed pin and divergent pin configuration provides a better stability when compared to lateral pins and parallel pin configuration ${ }^{19}$. Use of threaded pins provides a good support than smooth pins in osteoporotic bones and prevents pin loosening. Percutaneous pinning is a minimally invasive procedure that offers good stability and early range of motion and least chances of stiffness when compared to open surgical plating ${ }^{20}$.

\section{Conclusion}

Percutaneous pinning with $\mathrm{k}$ - wires is a minimally invasive day care procedure meeting the patient demands. The anatomical reduction and radiological parameters are found to be maintained by crossed pinning providing a successful functional outcome. The fracture union time on an average is found to be around 6 weeks. Percutaneous pinning is a valuable procedure to prevent secondaryfracturedisplacements with least complication rate. Further, the procedure is so economical and less time consuming and doesn't need a longer learning curve compared other modalities of treatment.

\section{Bibliography}

[1]. Rayhack JM. The history and evolution of percutaneous pinning of displaced distal radius fractures. OrthopClin North Am 1993 ; $24: 287-300$

[2]. Munson GO, Gainor BJ. Percutaneous pinning of distal radius fractures. J Trauma 1981;21: 1032-5.

[3]. Cummings SR, Kelsey JL, Nevitt MC, O’Dowd KJ. Epidemiology of osteoporosis and osteoporotic fractures. Epidemiology Rev. 1985;7:178-208

[4]. Fernandez DL ,Jupiter JB, editors. Fractures of the distal radius; Apractical approach to management. New York. NY; Springer Verlag; 1996

[5]. Short WH, Palmer AK, Werner FW, et al: A biomechanical study of distal radial fractures, J Hand Surg [Am] 12:529-534, 1987

[6]. Medoff RJ: Essential radiographic evaluation for distal radius fractures, Hand Clin 21:279-288, 2005

[7]. Gupta R, Raheja A, Modi U. Colles fracture management by percutaneous crossed pin fixation versus plaster of Paris cast immobilization. Orthopedics 999; 22: 680-82.

[8]. Kreder HJ, Hanel DP, McKee M, et al: Consistency of AO fracture classification for the distal radius, J Bone Joint Surg Br 78:726731,1996

[9]. Crawford AJ, David LH. Elbow and Forearm. In: Lesly J, editor. Outline of Fractures including Joint Injuries, 11th ed. Edinburgh: Churchill Livingstone; 1999. p.164-73

[10]. Trumble TE, Schmitt SR, Vedder NB. Factors affecting functional outcome of displaced intra-articular distal radius fractures. J Hand Surg1994; 19-A : 325-340.

[11]. Kapandji AI, Epinette JA: Colles' fractures: treatment by double intrafocal wire fixation. In Razemon JP, Fisk GR : The Wrist, New York, Churchill Liv-ingstone, 1988:65-73

[12]. Szabo RM, Weber SC. Comminuted intrarticular fractures of the distal radius. ClinOrthop 1988; 230:39-48

[13]. Clancey GJ. Percutaneous Kirschner Wire Fixation of Colles' Fractures. JBJS1984; Vol 66-A (7):1008-14

[14]. Mah ET, Atkinson RN. Percutaneous Kirschner wire stabilization following closed reduction of Colles' fractures. J Hand Surg1992 ; 17-B : 55-62.

[15]. Lidstrom A: Fracture of the distal end of the radius. A clinical and statistical study of end results, ActaOrthop.Scandsuppl; 1959;41(1).

[16]. Cherian Jacob, anoop ,nithin Thomas Functional and Radiological Outcomes of Distal Radius Fractures Treated with Closed Reduction and Percutaneous Five Pin Technique

[17]. Frykman G. Fracture of the distal radius including sequelaeshoulder .A clinical and experimental study.ActaOrthopScand 1967; Suppl-108: 3 .

[18]. Gartland JJ, Werley CW. Evaluation of healed Colles' fractures. JBJS 1951; 33-A:895-907.

[19]. DePalma AF: Comminuted fractures of the distal end of the radius treated by ulnar pinning, J Bone Joint Surg Am 34:651-662, 1952

[20]. Naidu SH, Capo JT, Moulton M, Ciccone W, Radin A, Hershey PA. Percutaneous pinning of distal radius fractures: a biomechanical study. J Hand Surg 1997; Vol 22-A:252-57

[21]. Text book of orthopaedics by Campbell 12th edition p2890-2894 